\title{
Interação entre as Políticas Fiscal e Monetária: uma Análise sobre o Regime de Dominância Vigente na Economia Brasileira
}

\section{The Interaction between Fiscal and Monetary Policies: an Analysis of the Current Dominance Regime in the Brazilian Economy}

\author{
Wellington Charles Lacerda Nobrega ${ }^{a}$ \\ Sinézio Fernandes Maia ${ }^{a}$ \\ Cássio da Nóbrega Besarria ${ }^{a}$
}

\begin{abstract}
Resumo: Este artigo tem o propósito de investigar o regime de dominância (monetária ou fiscal) vigente na economia brasileira no período de 2003 a 2015. Para isso, empregase o modelo de vetores autorregressivos (VAR) como primeiro exercício. Os resultados obtidos nessa etapa sugerem a existência de uma relação de dominância monetária. Entretanto, verifica-se uma mudança estrutural na relação entre as variáveis no ano de 2011. Por meio de regressões múltiplas da equação da dívida com inclusão de variáveis dummies, verifica-se que a oferta monetária passa a apresentar relação negativa com a dívida, sugerindo que a expansão da base monetária foi utilizada para estabilizar as contas públicas. Esse resultado sugere que há indícios de um regime de dominância fiscal para o período recente, o que é corroborado pelo método VAR com mudança markoviana (MS-VAR), pelo qual é possível identificar a existência de dois regimes bem definidos no período analisado.
\end{abstract}

Palavras-chave: Dominância monetária. Dominância fiscal. Política monetária. MSVAR.

\begin{abstract}
This paper aims to investigate the dominance regime (monetary or fiscal) prevailing in Brazilian economy in the period from 2003 to 2015. For this, an autoregressive vectors model (VAR) was used as first approach. The results of this step suggest the existence of a monetary dominance relationship. However, a structural change in the relationship between variables was verified. And, through multiple regressions of debt equation with the inclusion of dummy variables, was found that the money supply began to show negative relationship with public debt, suggesting that the expansion of the monetary base was used to stabilize public accounts. This results suggests that there is evidence of a fiscal dominance regime for the recent period. Fact borne out by the Markov-Switching autoregressive vectors model (MS-VAR), where it identified the existence of two clearly defined regimes in the analyzed period.
\end{abstract}

Keywords: Monetary dominance. Fiscal dominance. Monetary policy. MS-VAR.

JEL Classification: C32; E52; E62.

a Universidade Federal da Paraíba (UFPB), Departamento de Economia, Programa de PósGraduação em Economia (PPGE). João Pessoa, Paraíba, Brasil. 


\section{Introdução}

As decisões de política monetária e fiscal se encontram no centro do debate econômico e político da maioria das economias ao redor do mundo. Não obstante a capacidade anticíclica de tais medidas, as autoridades monetária e fiscal possuem objetivos e instrumentos diferentes, o que pode levar a um comportamento antagônico na falta de coordenação entre ambas.

O debate acerca da importância da coordenação entre política fiscal e monetária foi estimulado pelo trabalho seminal de Sargent e Wallace (1981), no qual esses autores descrevem dois possíveis cenários de interação entre ambas as políticas econômicas que resultam em duas formas de dominância política: a dominância monetária ou a dominância fiscal, podendo a postura da autoridade fiscal, em relação aos gastos públicos, influenciar diretamente a eficiência da política monetária.

No Brasil, adotou-se o regime de metas para a inflação a partir de 1999, com o objetivo principal de exercer maior controle sobre a inflação, tornando a taxa de juros (Selic) o principal instrumento de controle do nível de preços da economia. Simultaneamente, o governo federal assumiu o compromisso de atingir uma meta para o superávit primário, no intuito de garantir a sustentabilidade da dívida pública. Esse conjunto de medidas tinha por finalidade sinalizar o comprometimento do governo federal com o controle da dinâmica inflacionária e manutenção da dívida pública em níveis sustentáveis.

Entretanto, a taxa de juros praticada no Brasil é notadamente mais elevada que a grande maioria das economias em desenvolvimento, com taxa média de $13.91 \%^{1}$ ao longo dos últimos dois anos. A título de comparação, Peru (3,25\%), Colômbia (4,50\%), Chile (3,00\%) e México (3,00\%) possuem a taxa básica de juros em um nível bastante inferior ao praticado no Brasil. A despeito do elevado juro, a taxa de inflação se apresenta em um patamar ainda elevado (10,67\% em dezembro de 2015), distanciando-se da meta de 4,50\% do governo. Nesse contexto, é inevitável o surgimento de questionamentos a respeito da capacidade de a taxa Selic influenciar o comportamento presente e futuro da taxa de inflação, assim como se a melhor estratégia de combate à inflação, no atual cenário em que se encontra a economia brasileira, é a adoção de regras de política monetária, tal como proposta por Taylor (1993). ${ }^{2}$

1 Taxa média calculada com base na Meta Selic divulgada pelo Banco Central do Brasil (BCB) entre as $186^{\circ}$ e $201^{\circ}$ reuniões do Comitê de Política Monetária (Copom).

2 Taylor (1993) trouxe ao debate a questão fundamental entre regras de política e o discricionarismo na consecução da política monetária, atentando para os possíveis ganhos de credibilidade obtidos junto aos agentes econômicos em virtude do fato de o governo seguir regras claras no combate à inflação. A regra de Taylor, conforme inicialmente proposta, descreve a reação do Banco Central em relação à inflação através de seus desvios em relação à meta preestabelecida e 
Uma das explicações para tal fenômeno está pautada na tese da dominância fiscal, na qual a condução da política fiscal é a principal causa da ineficácia da política monetária, motivando a manutenção de uma elevada taxa de juros. Por um lado, o risco de default da dívida pública pressiona uma elevação do prêmio de risco, por outro, a expectativa de uma futura monetização da dívida eleva as expectativas inflacionárias. A elevação dos juros (política monetária restritiva) conduz a uma ampliação dos gastos com serviço da dívida, ampliando ainda mais o risco de insolvência. Nesse contexto, surgem os efeitos indesejados que caracterizam o regime de dominância fiscal, no qual a política monetária restritiva, ao invés de conter o crescimento da inflação - via redução da demanda e apreciação cambial -, provoca o agravamento do viés inflacionário.

A atual conjuntura da economia brasileira suscita uma maior investigação a respeito do regime de dominância vigente no país: o Brasil se encontra sob o regime de dominância monetária ou dominância fiscal? Há evidências de uma mudança de regime no período recente? A preocupação com o desempenho das contas públicas tem sido tema de debate, levantando questionamentos acerca da postura adotada pelo governo em relação ao andamento da política fiscal. Por exemplo, Schymura $(2015$, p. 8) argumenta:

A atual conjuntura brasileira apresenta características que podem sugerir o risco de dominância fiscal. [...] Não há dúvidas que as expectativas fiscais não são positivas e que a dificílima situação política cria nos agentes uma sensação de impotência do governo para lidar com o desafio das contas públicas.

Nesse cenário, a fragilidade das contas públicas pode ser considerada um importante indicador do regime de dominância vigente, uma vez que reflete as atitudes do governo central. Não obstante, as previsões para o superávit primário brasileiro - principal instrumento de estabilização da relação dívida/PIB - mostram-se bastante pessimistas, de acordo com o Relatório da inflação de dezembro de 2015:

O governo, considerando o cenário de menor arrecadação e de dificuldade na ampliação do contingenciamento de despesas, encaminhou projeto de lei ao Congresso Nacional estabelecendo nova meta de resultado primário para 2015, mediante alterações na Lei de Diretrizes Orçamentárias. A proposta foi aprovada em dezembro e estabelece que a meta para o Governo Central passa de superávit de $\mathrm{R} \$ 5,8$ bilhões para déficit de $\mathrm{R} \$ 51,8$ bilhões, podendo totalizar até $\mathrm{R} \$ 119,9$ bilhões se houver frustração de receitas previstas com concessões e permissões ou pagamentos de despesas de equalização de taxas e/ou subsídios acumulados de exercícios anteriores (BRASIL, 2015a, p. 33).

dos ciclos de negócios. Posteriormente, Clarida et al. (1998) propõem uma versão prospectiva da regra original, na qual a reação ocorria em virtude das expectativas inflacionárias. 
Diante do exposto, o presente artigo tem como objetivo geral investigar o regime de dominância vigente na economia brasileira. Para alcançar esse propósito, utiliza-se um modelo de vetores autorregressivos (VAR) compreendendo o período entre 2003 e 2015. Além disso, por objetivos específicos, pretende-se investigar se houve mudança estrutural no período recente. Para isso, realizam-se estimações de modelos com variáveis dummy por meio dos métodos de momentos generalizados (GMM) e de mínimos quadrados ordinários (MQO). Ademais, também estima-se um modelo VAR com mudança markoviana (MS-VAR) com a finalidade de se captar uma possível mudança de regime. Esses objetivos auxiliarão a compreensão da interação entre as variáveis fiscais e monetárias e seus desdobramentos.

Os resultados obtidos na primeira análise mostram que, de forma geral, o regime de dominância prevalecente na economia brasileira é o regime de dominância monetária, estando em consonância com os resultados encontrados por estudos anteriores, tais como os de Aguiar (2007), Gadelha e Divino (2008), Araújo e Besarria (2014), Ferreira (2015), entre outros. Entretanto, as etapas seguintes deste artigo identificam e modelam uma mudança estrutural, ocorrida no ano de 2011, na relação entre as variáveis tratadas. Referente a isso, os resultados obtidos através do MS-VAR indicam que, a partir desse momento, a oferta monetária passa a apresentar uma relação negativa com a dívida, sugerindo que a expansão da base monetária foi utilizada com o objetivo de fechar as contas públicas, levantando alguns indícios da vigência de um regime de dominância fiscal para o período recente.

O presente trabalho é composto por cinco seções, incluindo esta introdução: a seção 2 apresenta uma breve revisão bibliográfica acerca do tema; a seção 3 discute os procedimentos metodológicos utilizados; a seção 4 expõe os resultados encontrados; e, por fim, a seção 5 trata das considerações finais e discussões.

\section{Revisão da Literatura}

Em um trabalho seminal, Sargent e Wallace (1981) introduzem um importante debate na literatura econômica, alertando para a importância da coordenação entre a política fiscal e a monetária. A hipótese desenvolvida vai contra a ideia monetarista de que a inflação é um fenômeno puramente monetário, sendo passível de controle permanente através da política monetária. Assim, esses autores descreveram dois possíveis cenários de interação entre as políticas econômicas, determinadas pela coordenação entre as autoridades fiscal e monetária: a dominância monetária ou fiscal. O argumento é o de que, na ausência de coordenação, a política fiscal desregrada pode tornar ineficaz o instrumento de política monetária na busca ou manutenção do controle inflacionário. 
O regime de dominância monetária é caracterizado por uma autoridade fiscal passiva, comprometida com a geração de receitas e orçamento equilibrado, no sentido de promover a estabilização da relação dívida/PIB. Nesse caso, a autoridade monetária não é forçada a monetizar a dívida no intuito de saldar o débito do governo.

Por outro lado, a dominância fiscal está associada a uma autoridade fiscal que determina unilateralmente seus orçamentos correntes e futuros, impondo o montante de receita que deverá ser gerada através da senhoriagem e da venda de títulos públicos. Nesse caso, a dívida pública não está associada a um superávit primário que seja capaz de estabilizar a razão dívida/PIB. A autoridade monetária perde o controle dos níveis de preços por precisar monetizar a dívida, a fim de gerar as receitas de senhoriagem necessárias à solvência do governo.

Outra corrente teórica voltada ao debate da coordenação entre as políticas monetária e fiscal, que atenta para o papel de grande importância da política fiscal no controle inflacionário, é conhecida por Teoria Fiscal do Nível de Preços (TFNP). Elaborada por Sims (1994) e Woodford (1994), a TFNP postula que a política monetária por si só é incapaz de controlar o nível de preços. À vista disso, a determinação do nível de preços da economia é essencialmente dada por intermédio da política fiscal.

Na proposição convencional, proposta por Sargent e Wallace (1981), a restrição dos gastos governamentais é satisfeita através da arrecadação tributária, emissão de títulos ou com a coleta de senhoriagem para qualquer nível de preços, igualando os valores presentes dos gastos e receitas, de forma a manter o orçamento equilibrado.

Em contraposição, na TFNP, ${ }^{3}$ defende-se que o valor presente da restrição orçamentária não é uma restrição sobre a política, mas sim uma condição de equilíbrio. Dessa forma, as expectativas dos agentes econômicos sobre a conduta da política fiscal determinam o nível de encaixes reais demandado e, portanto, o nível de preços compatível com o equilíbrio. Ou seja, quando o equilíbrio orçamentário do governo é alterado, o nível de preços move-se de forma a trazer o sistema de volta ao equilíbrio.

Blanchard (2004) e Favero e Giavazzi (2004) estão na vanguarda de outra importante vertente teórica que expandiu a análise para o contexto de uma economia aberta, evidenciando o risco de default como um mecanismo no qual os bancos centrais de economias emergentes podem perder o controle da inflação e conduzir a economia a um regime de dominância fiscal.

3 O regime político é dito ricardiano (dominância monetária) se o superávit primário é calibrado - dado o nível de preços - de forma a satisfazer a restrição orçamentária do governo. Por outro lado, em um regime não ricardiano (dominância fiscal), o superávit não é calibrado de forma a satisfazer a restrição orçamentária do governo para todo nível de preços. 
A proposta teórica de Blanchard (2004) foi que o uso da política monetária como mecanismo de controle inflacionário em uma economia aberta e com regime de metas de inflação pode, sob determinadas condições, gerar resultados contrários aos propostos, ou seja, pode haver uma expansão dos preços ao invés de redução. As condições para que esse efeito seja observado estão fortemente ligadas às condições fiscais da economia. Nesse sentido, quando o termo "condição fiscal da economia" é mencionado, é importante ter em mente três possíveis estágios: montante inicial da dívida pública; proporção da dívida indexada à moeda estrangeira; e aversão ao risco por parte dos investidores estrangeiros, sendo que há uma relação direta entre esses termos e a chance de a política monetária reduzir sua capacidade de combater a inflação.

Em condições normais, a elevação da taxa de juros atua sobre a economia através de dois canais principais: a) redução da demanda agregada devido à diminuição do consumo e investimento; b) taxa de câmbio, uma vez que maiores taxas de juros representam maiores lucros a investidores, estimulando a demanda por títulos públicos, fato que acarreta uma maior entrada de capitais estrangeiros na economia e conduz a uma apreciação cambial. De modo geral, os dois canais de transmissão de política monetária apresentados mostram os efeitos de uma expansão na taxa de juros sobre a dinâmica inflacionária. Entretanto, no cenário econômico adverso descrito por Blanchard (2004), a elevação dos juros implica uma elevação dos gastos com o montante de serviço da dívida, elevando o risco de default percebido pelos investidores, o que reduz a atratividade dos títulos públicos, causando influxo de capitais e, por consequência, depreciação cambial.

Direcionando a análise para a literatura científica brasileira, diversos trabalhos tratam dessa temática e buscam avaliar qual é o regime de dominância vigente na economia brasileira em distintos períodos. Os trabalhos recentemente realizados por Tanner e Ramos (2003), Aguiar (2007), Gadelha e Divino (2008), Araújo e Besarria (2014) e Ferreira (2015) verificam que o Brasil se encontra sob o regime de dominância monetária.

Por outro lado, Blanchard (2004) e Favero e Giavazzi (2004) constatam que o Brasil, no ano de 2002, esteve sob um regime de dominância fiscal. Mais recentemente, esse resultado também foi encontrado por Ázara (2006) e Marques Júnior (2009). O Quadro 1 apresenta o resumo de alguns importantes trabalhos relevantes. 
Quadro 1 - Resumo dos trabalhos sobre coordenação entre política monetária e fiscal

\begin{tabular}{|l|c|c|c|}
\hline \multicolumn{1}{|c|}{ Autor(es) } & Método & Período & Resultado \\
\hline Tanner e Ramos (2003) & VAR & $1990-2001$ & DM \\
\hline Fialho e Portugal (2005) & MS-VAR & $1994-2004$ & DM \\
\hline Ázara (2006) & AR(1)/MQO & $1999-2005$ & DF \\
\hline Aguiar (2007) & VAR & $1999-2007$ & DM \\
\hline Gadelha e Divino (2008) & VAR & $1995-2005$ & DM \\
\hline Marques Júnior (2009) & AR(1)/MQO & $2003-2008$ & DF \\
\hline Ornellas e Portugal (2011) & DSGE & $1999-2009$ & DF \\
\hline Maka (2013) & SVAR & $2001-2008$ & DM \\
\hline Ferreira (2015) & SVAR & $2003-2013$ & DM \\
\hline
\end{tabular}

Fonte: Elaboração própria.

Nota: Dominância monetária (DM); dominância fiscal (DF).

A partir do Quadro 1, é possível observar que não existe consenso acerca do regime de dominância vigente na economia brasileira, uma vez que os estudos aplicados ao Brasil não compartilham um resultado comum, mesmo que em alguns casos seja analisado praticamente a mesma janela temporal. Nessa perspectiva, a vigência do regime de dominância fiscal parece ser especificamente relacionada ao período investigado, muito ligado às condições macroeconômicas e políticas do período em questão, diferentemente da dominância monetária que aparenta ser o caso geral.

Nesse ponto, é importante ressaltar a limitação dos modelos lineares na identificação dos regimes de dominância, uma vez que a própria linearidade dos parâmetros do método pode ser um fator limitante no tocante à análise das interações entre as políticas fiscal e monetária, devido à impossibilidade dessas modelagens captarem uma possível mudança na relação dos parâmetros, tanto em breves momentos, quanto ao longo da janela amostral, tal como períodos específicos de política fiscal ativa ou mudança nas diretrizes de condução da política fiscal, por exemplo. Buscando-se tornar o presente trabalho robusto a tal problema, optou-se por utilizar um modelo de autorregressão vetorial com mudança markoviana nos parâmetros, conforme exposto na próxima seção. Esse método permite a estimação de parâmetros variantes no tempo, condicionados a um determinado número de regimes. 


\section{Procedimentos Metodológicos}

Na década de 1980, uma importante crítica aos modelos econométricos utilizados até então, principalmente em virtude da grande quantidade de restrições de identificação e também em relação à forma estática desses modelos, foi realizada por Sims (1980). Nesse contexto, o método VAR, conforme proposto pelo autor, trata todas as variáveis integrantes do sistema simetricamente e sem qualquer restrição em relação à dependência ou independência entre elas, em contrapartida aos modelos de equações simultâneas.

A abordagem empírica a partir de modelos VAR tornou-se amplamente ${ }^{4}$ utilizada na literatura para o estudo das relações entre as variáveis macroeconômicas, principalmente por possibilitar a análise das relações dinâmicas entre as variáveis quando submetidas a um choque, auxiliando no melhor entendimento das relações contemporâneas entre as variáveis. O VAR(p)-padrão, na forma reduzida, é representado por:

$$
\mathrm{x}_{\mathrm{t}}=v+\mathrm{A}_{1} \mathrm{x}_{\mathrm{t}-1}+\cdots+\mathrm{A}_{\mathrm{p}} \mathrm{x}_{\mathrm{t}-\mathrm{p}}+\varepsilon_{\mathrm{t}}
$$

em que $x_{t}$ é um vetor $(n \times 1)$ contendo as $n$ variáveis inclusas no modelo VAR, $v$ é o vetor ( $n \times 1)$ de interceptos, $\mathrm{A}_{\mathrm{i}}, \mathrm{i}=0,1, \ldots, \mathrm{k}$ são matrizes $(n \times n)$ de coeficientes e $\varepsilon_{\mathrm{t}}$ é o vetor $(n \times 1)$ de resíduos.

Os modelos VAR têm as suas limitações, que são objetos de crítica. Uma limitação recorrentemente citada é a suposição de linearidade na relação entre as variáveis do sistema. Nesse contexto, a partir do VAR padrão desenvolvido por Sims (1980), associado aos modelos de mudança de regime de processos markovianos, ${ }^{5}$ Krolzig (1997) desenvolve o chamado MS-VAR.

De acordo com Krolzig (1997), os modelos MS-VAR podem ser considerados como generalizações dos modelos VAR(p), em que os parâmetros são variantes no tempo. Entretanto, o processo pode ser invariante quando condicionado a uma variável não observável $\left(\mathrm{s}_{\mathrm{t}}\right)$, a qual indica o regime prevalecente no momento. Dessa forma, o modelo MSM(M)-VAR( $p)$ ajustado na média pode ser expresso por:

$$
\mathrm{Y}_{\mathrm{t}}-\mu\left(\mathrm{s}_{\mathrm{t}}\right)=\mathrm{A}_{1}\left(\mathrm{~s}_{\mathrm{t}}\right)\left(\mathrm{y}_{\mathrm{t}-1}-\mu\left(\mathrm{s}_{\mathrm{t}-1}\right)\right)+\cdots+\mathrm{A}_{\mathrm{p}}\left(\mathrm{s}_{\mathrm{t}}\right)\left(\mathrm{y}_{\mathrm{t}-\mathrm{p}}-\mu\left(\mathrm{s}_{\mathrm{t}-\mathrm{p}}\right)\right)+\mathrm{u}_{\mathrm{t}}
$$

$4 \quad$ Vale ressaltar que o BCB utiliza modelos VAR como "[...] instrumento de análise e, principalmente, de previsão de inflação desde a implementação do regime de metas para a inflação, em junho de 1999 [...]" (BRASIL, 2010, p. 111).

5 Um processo markoviano tem por base um conjunto de objetos e estados, forma que: em qualquer instante $(t)$, os objetos devem estar em algum estado; e que a probabilidade do objeto estar em determinado estado é dependente apenas do estado em que está o sistema no período $(t)$. 
no qual $p$ é a ordem de defasagem, $u_{t}$ é o erro condicionado ao regime, $k$ é a dimensão do vetor de variáveis e $M$ é o número de regimes. Os termos $\mu, \mathrm{A}_{1}\left(\mathrm{~s}_{\mathrm{t}}\right), \ldots, \mathrm{A}_{\mathrm{p}}$ $\left(s_{t}\right), \sum\left(s_{t}\right)$ representam as funções de mudança que descrevem a dependência de $\mu, \mathrm{A}_{1}, \ldots, \mathrm{A}_{\mathrm{p}}, \Sigma$, de acordo com o regime realizado $\left(\mathrm{s}_{\mathrm{t}}\right)$. A probabilidade de transição entre regimes é expressa por:

$$
\mathrm{P}_{\mathrm{ij}}=\operatorname{Pr}\left(\mathrm{s}_{\mathrm{t}+1}=\mathrm{j} \mid \mathrm{s}_{\mathrm{t}}=\mathrm{i}\right), \sum_{\mathrm{j}=1}^{\mathrm{m}}=1 \forall_{\mathrm{i}}, \mathrm{j} \in\{1,2, \ldots, \mathrm{m}\}
$$

em que $P_{\mathrm{ij}}$ representa a probabilidade de, estando no regime $i$, no instante $t+1$ ocorra mudança para o regime $j$. As probabilidades de transição também podem ser representadas em forma matricial, de forma a melhor apresentar as transições de probabilidade adjacente a cada regime, considerando-se dois regimes:

$$
T=\left|\begin{array}{cc}
p_{11} & 1-p_{22} \\
1-p_{11} & p_{22}
\end{array}\right|
$$

em que $p_{11}$ representa a probabilidade de, estando no regime 1, permanecer-se nele, e $1-\mathrm{p}_{22}$ representa a probabilidade de, estando no regime 1 , ocorrer uma transição para o regime 2. O raciocínio é análogo para a segunda linha da matriz.

No que diz respeito ao conjunto de dados utilizados no presente artigo, as séries de tempo referentes à relação dívida líquida do setor público, necessidade de financiamento do setor público, taxa de câmbio efetiva real, taxa de juros e as expectativas de inflação foram obtidas através do sistema gerenciador de séries temporais (SGS) disponível no site do Banco Central do Brasil (BCB). Já os dados referentes à base monetária e ao spread soberano, EMBI+, foram extraídos junto à plataforma Ipeadata.

Todas as séries temporais utilizadas nesta pesquisa estão expressas em periodicidade mensal, de janeiro de 2003 a julho de 2015, totalizando uma amostra de 151 observações. A escolha desse corte temporal foi motivada, principalmente, em virtude da disponibilidade das informações referentes à dívida pública, que se encontram acessíveis apenas a partir de meados de 2002. O Quadro 2 apresenta o resumo das variáveis. 
Quadro 2 - Descrição dos dados

\begin{tabular}{|c|c|c|c|c|}
\hline Série & Variável & Unidade de medida & Fonte & Código \\
\hline $\begin{array}{l}\text { Dívida líquida do setor pú- } \\
\text { blico - Total - setor público } \\
\text { consolidado }\end{array}$ & DLSP & $\begin{array}{l}\text { (\%) PIB ao ano, acumula- } \\
\text { do, mensal }\end{array}$ & $\mathrm{BCB}$ & 4513 \\
\hline $\begin{array}{l}\text { Necessidade de financia- } \\
\text { mento do setor público - } \\
\text { resultado nominal - total }\end{array}$ & NFSP & $\begin{array}{l}\text { (\%) PIB ao ano, acumula- } \\
\text { do, mensal }\end{array}$ & $\mathrm{BCB}$ & 5727 \\
\hline $\begin{array}{l}\text { Expectativas de inflação } \\
\text { (IPCA) - acumulada para os } \\
\text { próximos } 12 \text { meses - me- } \\
\text { diana }\end{array}$ & EXPECT & $\begin{array}{l}\text { (\%) ao ano, acumulado, } \\
\text { mensal }\end{array}$ & $\mathrm{BCB}$ & - \\
\hline Taxa de juros - Selic & SELIC & $\begin{array}{l}\text { (\%) ao ano, acumulado, } \\
\text { mensal }\end{array}$ & $\mathrm{BCB}$ & 4390 \\
\hline $\begin{array}{l}\text { Taxa de câmbio efetiva real } \\
\text { (IPCA) }\end{array}$ & CAMBIO & $\begin{array}{l}\text { Índice mensal, } 1994.06 \\
=100\end{array}$ & $\mathrm{BCB}$ & 11752 \\
\hline $\begin{array}{l}\text { Necessidade de financia- } \\
\text { mento do setor público - } \\
\text { resultado primário }\end{array}$ & NFSSP & $\begin{array}{l}\text { (\%) PIB ao ano, acumula- } \\
\text { do, mensal }\end{array}$ & $\mathrm{BCB}$ & 5793 \\
\hline M1 - fim de período & M1 & (\%) PIB, mensal & $\begin{array}{l}\text { Ipea- } \\
\text { data }\end{array}$ & - \\
\hline EMBI+ (risco-Brasil) & EMBI & Média mensal & $\begin{array}{l}\text { J. P. } \\
\text { Morgan }\end{array}$ & - \\
\hline Variável dummy & $\mathrm{D}_{1 \mathrm{t}}$ & - & - & - \\
\hline
\end{tabular}

Fonte: Elaboração própria.

Nota (*): A acumulação das séries diz respeito aos últimos 12 meses, com exceção da expectativa de inflação, que é calculada com base nas expectativas para a inflação acumulada nos próximos 12 meses.

Vale ressaltar que todas as séries de dados foram tomadas em seus logaritmos naturais. Além disso, foi realizado o ajuste sazonal através do método X-13 Arima. Um princípio básico dos modelos que fazem uso de séries temporais é que os dados distribuídos ao longo do tempo sejam estáveis ou estacionários. No intuito de testar a presença de raiz unitária nas séries de dados, foram realizados os testes de raiz unitária convencionais (ADF, PP, KPSS, ERS) e testes de raiz unitária na presença e quebras estruturais (PERRON, 1989; ZIVOT-ANDREWS, 1992; LEE-STRAZICICH, 2003, 2013). Os resultados dos testes de raiz unitária se encontram no Apêndice A.

A partir dos testes convencionais de raiz unitária, não foi possível rejeitar a hipótese nula, de raiz unitária, para as variáveis em nível com exceção da variável referente às expectativas inflacionárias. Esse resultado é corroborado pelos testes de raiz unitária com quebra estrutural. 
Levando-se em consideração esse fato, utilizou-se o filtro Hodrick-Prescott (HP) ${ }^{6}$ para transformar as séries em desvios em relação à tendência, eliminando os termos determinísticos das variáveis e obtendo-se dados com comportamento estável. Uma vez que a utilização do filtro HP não garante, por si só, a estacionariedade das séries, os testes convencionais (ADF, PP, KPSS, ERS) de raiz unitária foram aplicados objetivando verificar a estacionariedade ou não estacionariedade das séries transformadas, e, de forma geral, os resultados indicam que todas as séries são estacionárias a 5,00\%.

\section{Resultados}

A presente seção apresenta os resultados obtidos a partir dos diferentes modelos empíricos aplicados neste artigo. Primeiro, na Subseção 4.1, é debatido os resultados encontrados a partir do modelo de Vetores Autorregressivos. Logo em seguida, a subseção 4.2 investiga uma possível mudança estrutural nas variáveis do modelo através de equações autoregressivas com a inclusão de variáveis dummies. Por fim, a subseção 4.3 apresenta os resultados referentes ao modelo de Vetores Autorregressivos com Mudança Markoviana, utilizado no intuito de captar as relações não lineares existentes entre as variáveis do modelo.

\subsection{Vetores Autorregressivos}

Previamente à estimação do modelo VAR, foram realizados testes para seleção do número ótimo de defasagens do modelo. Os resultados indicaram duas e quatro defasagens. Entretanto, o modelo com duas defasagens apresentou autocorrelação residual, sendo, portanto, descartado. Em relação aos resíduos do modelo com quatro defasagens, foi possível rejeitar a hipótese da existência de autocorrelação serial. Além disso, todas as raízes inversas do polinômio característico autorregressivo situam-se dentro do círculo unitário, indicando que o modelo é estável. Os resultados dos testes se encontram no Apêndice A.

As análises das funções de resposta ao impulso do modelo VAR serão voltadas, tal como enfatiza a literatura, para os principais canais de investigação das relações de dominância monetária e fiscal. Portanto, serão analisados os efeitos dos choques positivos nas séries da dívida pública e taxa Selic sobre as demais variáveis de interesse. A Figura 1 apresenta os efeitos do choque expansionista na dívida pública, sendo importante destacar que os efeitos desse choque serão avaliados a partir da mediana da função impulso-resposta.

$6 \quad$ O parâmetro utilizado no filtro HP foi $\lambda=14.400$. 
Figura 1 - Funções resposta ao impulso na dívida pública
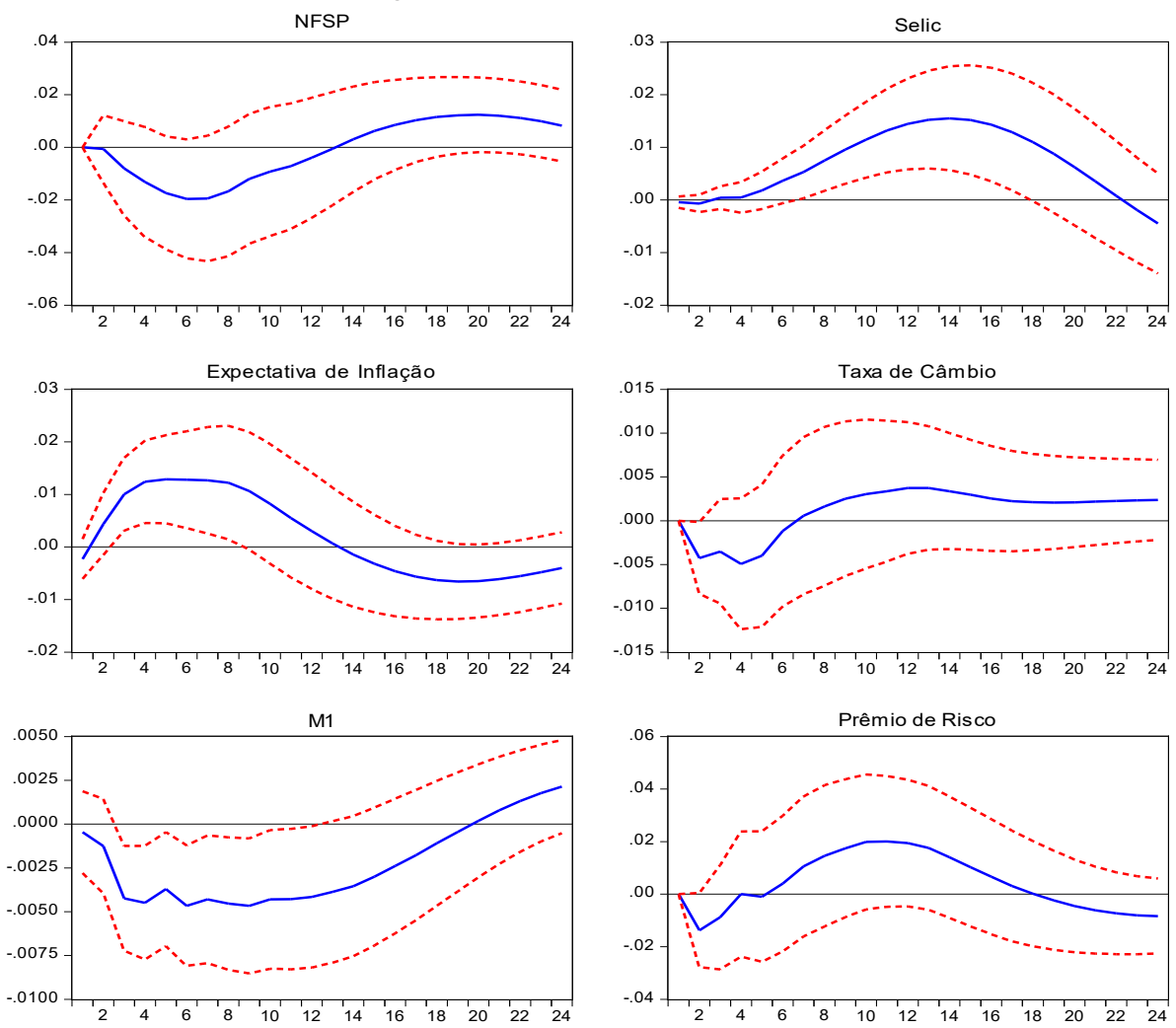

Fonte: Elaboração própria.

Nota: Identificação do choque na DLSP via decomposição de Cholesky (um desvio padrão). As linhas tracejadas correspondem ao intervalo de confiança de 95,00\%.

O gráfico superior esquerdo mostra que um choque na dívida pública afeta a necessidade de financiamento do setor público de forma negativa no primeiro momento, sendo revertida após 12 períodos, tornando-se superior, em magnitude, ao estágio inicial.

Esse comportamento sugere que há resposta de curto prazo no sentido de ampliação da geração de superávits com o intuito de manter a relação DLSP/PIB estável, apontando para a ideia de que o governo atua com a finalidade de preservar a dívida pública em níveis sustentáveis. Ademais, esse resultado é um importante indicador da vigência de um regime de dominância monetária, conforme proposto por Sargent e Wallace (1981), uma vez que apresenta a existência de uma autoridade fiscal comprometida com a estabilização da dívida através de políticas de superávit primário, estando em consonância com os resultados obtidos por Gadelha e Divino (2008), Araújo e Besarria (2014) e Ferreira (2015). 
Percebe-se que a expansão na dívida pública afetou positivamente as expectativas inflacionárias dos agentes econômicos e, em decorrência desse efeito, o $\mathrm{BCB}$ respondeu à expansão nos preços via aumento na taxa de juros. Esse mecanismo pode explicar, em parte, a reversão na trajetória da necessidade de financiamento do setor público (NFSP) a partir do décimo segundo mês.

Apesar de já descrito anteriormente, é importante acrescentar uma informação adicional em relação à resposta da Selic à elevação das expectativas inflacionárias. Nota-se que a expansão na dívida tem efeito contemporâneo na inflação. Apesar disso, a resposta (da Selic) ocorre após quatro meses desse choque. Esse resultado sugere que a autoridade monetária persegue o controle das perspectivas de inflação com certa defasagem e sua decisão acaba sendo afetada, indiretamente, pelas decisões de política fiscal. Ferreira (2015) também chama atenção para o efeito indireto do choque de dívida na Selic, sugerindo que a política monetária brasileira não é totalmente independente, uma vez que a taxa de juros é afetada pela trajetória da dívida pública. Apesar disso, Ornellas e Portugal (2011) ressaltam que o Brasil possui baixo grau de dominância fiscal, o que significa que a autoridade monetária possui autonomia no combate à inflação.

Além desses efeitos, verifica-se que, no primeiro período após o choque na dívida líquida do setor público (DLSP), tem-se uma resposta negativa do EMBI e do câmbio, indicando redução do risco e apreciação da moeda doméstica. Entretanto, no mês seguinte ao choque ocorre uma reversão gradual, fato que conduz as variáveis a níveis superiores ao inicial, sugerindo ampliação do risco e depreciação cambial. Essas respostas evidenciam que o grau de endividamento público afeta diretamente a avaliação externa da economia brasileira, conforme argumenta Gadelha e Divino (2008).

O comportamento inicial do câmbio e do prêmio de risco merece ser investigado com mais cuidado. Conforme argumentado anteriormente, o choque na dívida pública provoca a elevação das expectativas inflacionárias. Nesse sentido, torna a moeda doméstica - em termos reais - mais valorizada, provocando também uma redução do prêmio de risco. Entretanto, à medida que os agentes econômicos incorporam as mudanças ocorridas em relação ao nível da dívida pública e à ampliação dos gastos com o serviço da dívida, o prêmio de risco se eleva, indicando que o novo estoque da dívida incorre em maior probabilidade de default, ampliando o spread demandado pelos investidores e conduzindo a depreciação cambial via fuga de capitais.

Por fim, a variável M1 responde de forma negativa a um choque na DLSP, conduzindo a um enxugamento da base monetária. Esse resultado é interessante, pois confirma a hipótese levantada de que o principal instrumento de manutenção da dívida pública em níveis sustentáveis é de fato o superávit primário. A constatação de que não há monetização frente a um choque na dívida sugere a vigência 
de um regime de dominância monetária, conforme argumenta Pastore, Gazzano e Pinotti (2014).

Prosseguindo-se a análise das funções resposta ao impulso, a Figura 2 apresenta as respostas das variáveis do modelo em decorrência de um choque contracionista de política monetária (aumento na taxa de juros Selic). Na parte superior esquerda e direita estão expostas as respostas da DLSP/PIB e da NFSP.

Figura 2 - Funções resposta ao impulso na taxa Selic
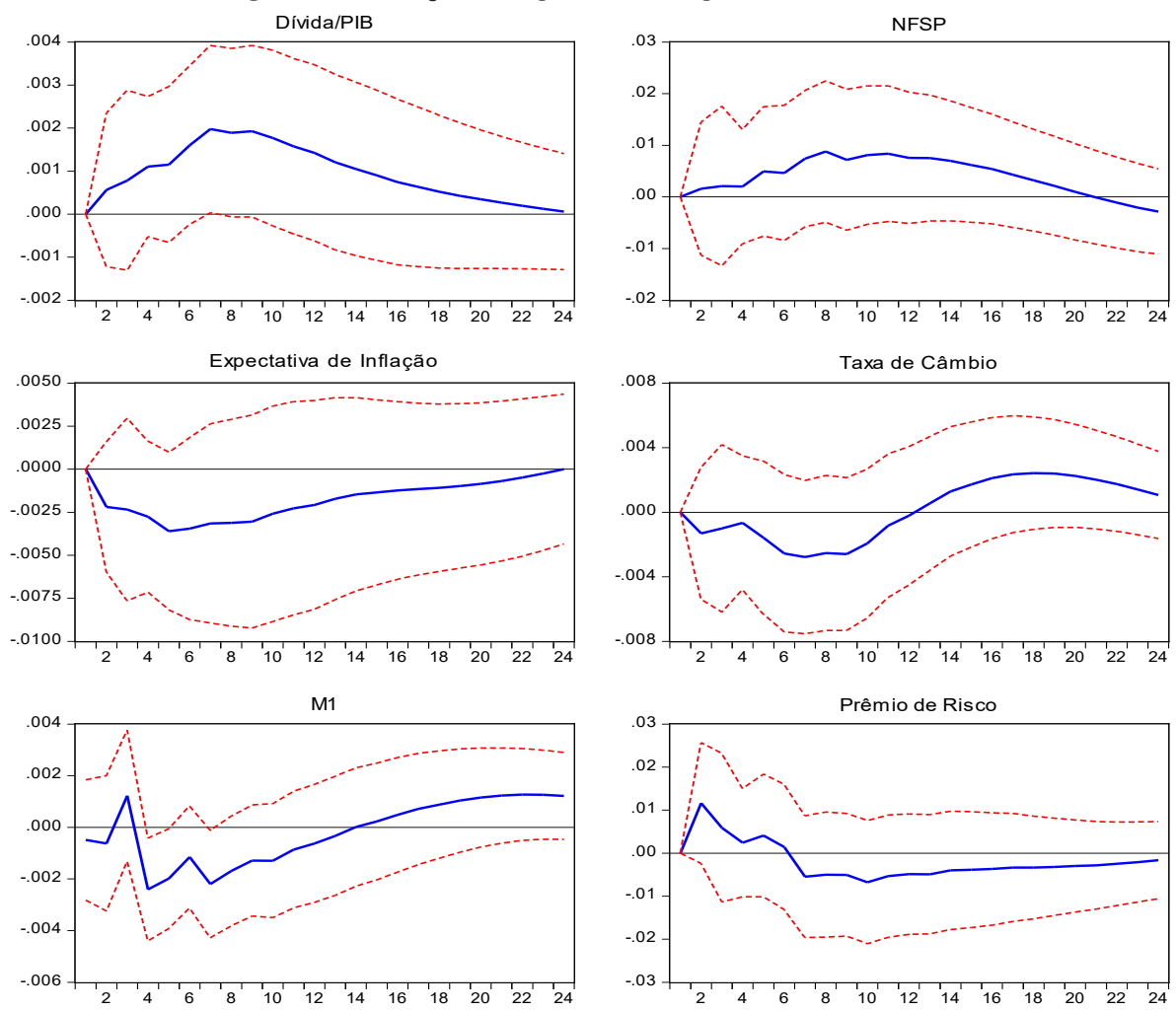

Fonte: Elaboração própria.

Nota: Identificação do choque na taxa Selic via decomposição de Cholesky (um desvio padrão). As linhas tracejadas correspondem ao intervalo de confiança de 95,00\%.

É possível observar que ambas compartilham respostas semelhantes, sendo esse comportamento explicado pela fração da dívida pública indexada à taxa de juros de curto prazo. Dessa forma, no momento em que a taxa de juros é elevada, o montante atrelado à Selic torna-se maior, ampliando a dívida. Da mesma forma, a necessidade de financiamento também possui um termo que relaciona o estoque da dívida atrelado à Selic, explicando a ampliação do endividamento através da elevação da demanda por financiamento do setor público. 
Os resultados sugerem que o choque de política monetária contracionista resulta em uma resposta negativa sobre as expectativas de inflação, demonstrando que a política monetária é capaz de influenciar ou acomodar as expectativas de inflação. Esse resultado está de acordo com a teoria convencional, em oposição ao efeito perverso da política monetária sobre a inflação prevalecente em um regime de dominância fiscal, conforme proposto por Sargent e Wallace (1981) e Blanchard (2004). Portanto, esse resultado sugere a existência de uma relação de dominância monetária.

Ademais, o choque de política monetária contracionista em relação ao câmbio mostra que inicialmente a elevação da Selic conduziu a uma apreciação cambial, resultado que prevalece até o $12^{\circ}$ período, quando é revertida em direção à desvalorização da moeda doméstica. Por outro lado, é possível observar uma leve piora, no curto prazo, no sentido de elevação do risco em decorrência do choque na Selic. Entretanto, no quarto período essa trajetória é revertida no sentido de redução do prêmio de risco, voltando a se estabilizar em torno do nível inicial.

De forma geral, esses resultados também sugerem a existência de um regime de dominância monetária, embora exista a leve elevação do risco em decorrência da ampliação do montante da dívida devido à elevação da Selic, comportamento revertido logo após o quarto mês, devido ao ganho de credibilidade da política monetária no controle das expectativas inflacionárias. Por outro lado, é possível observar uma forte apreciação cambial que se estende por aproximadamente 12 períodos. Esses resultados sugerem que não há prevalência do regime de dominância fiscal, conforme proposto por Blanchard (2004), reforçando os resultados encontrados em relação à função resposta ao impulso na dívida, na qual o regime de dominância vigente é o monetário.

Vis-à-vis, os resultados encontrados através do modelo VAR sugerem a existência de uma autoridade fiscal preocupada com a estabilização da relação DLSP/ PIB através do superávit primário. Por outro lado, mostram também que a política monetária é um instrumento crível no controle inflacionário. Portanto, os resultados obtidos utilizando essa abordagem metodológica levam à conclusão de que o Brasil se encontra sob a vigência de um regime de dominância monetária, conforme proposto por Sargent e Wallace (1981) e Blanchard (2004) - que estão em concordância com os resultados encontrados por Tanner e Ramos (2003), Aguiar (2007), Gadelha e Divino (2008), Araújo e Besarria (2014) e Ferreira (2015) -, sendo uma característica presente em todos os estudos que adotaram períodos de tempo mais longos. Assim, a dominância fiscal parece ser um caso isolado ou específico, muito ligado ao período de análise, diferentemente da dominância monetária, que parece ser o caso geral. 


\subsection{Avaliando a Mudança de Regime}

Os resultados da seção 4.1 sugerem que o Brasil se encontra sob um regime de dominância monetária. Entretanto, o comportamento recente das variáveis macroeconômicas levanta questionamentos acerca do resultado obtido. Dessa forma, torna-se necessária uma investigação mais aprofundada em relação a possíveis mudanças no comportamento recente da autoridade fiscal e que podem sugerir resultados que diferem do encontrado na seção anterior.

A análise será direcionada às relações existentes entre a dívida líquida (DLSP), necessidade de financiamento nominal (NFSP), necessidade de financiamento primário (NFSSP) e oferta monetária (M1), em virtude da possibilidade de avaliar através dessas se, de fato, há o esforço fiscal necessário para a estabilização da relação DLSP/PIB (dominância monetária) ou, ao invés disso, há monetização da dívida no intuito de obter receitas de senhoriagem necessárias à solvência do governo. Nesse caso, a manutenção da proporção DLSP/PIB é realizada através da emissão de moeda, e não pela disciplina fiscal (dominância fiscal). Serão estimados dois modelos alternativos, diferenciando-se um do outro pela variável referente à necessidade de financiamento, nominal ou primário, inserida na equação de regressão. Portanto, a equação da dívida pública pode ser expressa por:

$$
\operatorname{DLSP}_{\mathrm{t}}=\mathrm{f}\left(\mathrm{NFSP}_{\mathrm{t}}, \mathrm{Ml}_{\mathrm{t}}\right)
$$

na qual os sinais da relação entre as variáveis e a dívida pública são: $\left[\frac{\partial D L P_{t}}{\partial N F S S_{t}}>0\right.$ indicando uma relação direta, em que a elevação de qualquer necessidade de financiamento (nominal ou primário) implica variações positivas sobre a dívida pública; e $\left[\frac{\partial D L S P_{t}}{\partial M_{t-1}}\right]<0$, para o caso de o aumento do estoque monetário exercer influência negativa sobre a dívida líquida.

O indício de mudança de comportamento na condução do esforço fiscal será captado a partir do teste de quebra estrutural em processos lineares proposto por Bai (1994). O resultado desse teste indicou que houve uma mudança no comportamento/relação entre essas variáveis em 2011, conforme a Tabela 1. 
Tabela 1 - Resultados dos modelos com dummies

\begin{tabular}{|c|c|c|c|c|c|}
\hline \multirow{2}{*}{ Variáveis } & \multicolumn{2}{|c|}{ Modelo (1) } & \multirow{2}{*}{ Variáveis } & \multicolumn{2}{|c|}{ Modelo (2) } \\
\hline & MQO & GMM & & MQO & GMM \\
\hline $\mathrm{NFSP}_{\mathrm{t}}$ & $\begin{array}{l}0.0510 * \\
(0.0001)\end{array}$ & $\begin{array}{l}0.0317^{*} \\
(0.0265)\end{array}$ & $\mathrm{NFSSP}_{\mathrm{t}}$ & $\begin{array}{l}0.0187^{*} \\
(0.0007)\end{array}$ & $\begin{array}{l}0.0166^{*} \\
(0.0295)\end{array}$ \\
\hline $\mathrm{D}_{1 \mathrm{t}} \mathrm{NFSP}_{\mathrm{t}}$ & $\begin{array}{l}-0.0093 \\
(0.7195)\end{array}$ & $\begin{array}{c}0.0332 \\
(0.4828)\end{array}$ & $\mathrm{D}_{1 \mathrm{t}} \mathrm{SP}_{\mathrm{t}}$ & $\begin{array}{c}0.0043 \\
(0.6703)\end{array}$ & $\begin{array}{c}0.0058 \\
(0.7447)\end{array}$ \\
\hline$M 1_{t-1}$ & $\begin{array}{l}0.2866 * \\
(0.0005)\end{array}$ & $\begin{array}{l}0.3774 * \\
(0.0011)\end{array}$ & $M 1_{t-1}$ & $\begin{array}{l}0.2519 * \\
(0.0030)\end{array}$ & $\begin{array}{l}0.3206 * \\
(0.0113)\end{array}$ \\
\hline $\mathrm{D}_{1 t} \mathrm{M} 1_{\mathrm{t}-1}$ & $\begin{array}{l}-0.4320^{*} \\
(0.0002)\end{array}$ & $\begin{array}{l}-0.5093^{*} \\
(0.0002)\end{array}$ & $\mathrm{D}_{1 \mathrm{t}} \mathrm{M} \mathrm{1}_{\mathrm{t}-1}$ & $\begin{array}{l}-0.5275^{*} \\
(0.0001)\end{array}$ & $\begin{array}{l}-0.5646 * \\
(0.0007)\end{array}$ \\
\hline $\mathrm{R}^{2}-\mathrm{Adj}$ & 0.1869 & 0.2731 & $\mathrm{R}^{2}-\mathrm{Adj}$ & 0.1784 & 0.2757 \\
\hline Teste-J & & 0.7323 & Teste-J & & 0.6704 \\
\hline Rank & & 7 & Rank & & 7 \\
\hline Quebra & 2011.02 & & Quebra & 2011.03 & \\
\hline
\end{tabular}

Fonte: Elaboração própria;

Nota: ( ) Probabilidade; (*) instrumentos utilizados: NFSP ${ }_{t-1}, N F S P_{t-1} D_{t}, M 1_{t-1}, M 1_{t-1} D_{t}$, NFSP $_{t-2}$ e NFSP ${ }_{t-3}$.

De acordo com Pastore, Gazzano e Pinotti (2014), esse ano foi marcado por uma mudança de regime na política econômica que, na prática, consistiu do abandono do tripé ${ }^{7}$ macroeconômico. O efeito dessa mudança no comportamento da relação entre as séries foi incluído no modelo a partir da inserção de variáveis dummies multiplicativas, tal como exposto na equação 6:

$$
\operatorname{DLSP}_{\mathrm{t}}=\beta_{0}+\beta_{1} \mathrm{NFSP}_{\mathrm{t}}+\beta_{2} \mathrm{Mi}_{\mathrm{t}-1}+\beta_{3} \mathrm{D}_{1 \mathrm{t}} \mathrm{NFSP}_{\mathrm{t}}+\beta_{4} \mathrm{D}_{1 \mathrm{t}} \mathrm{Mi}_{\mathrm{t}-1}
$$

Os resultados da estimação da equação 6, obtidos a partir dos métodos MQO e GMM, estão apresentados na Tabela 1.

Em relação às necessidades de financiamento, pode-se observar que, no período anterior à inserção da variável dummy, a relação para com a dívida líquida se mostra estatisticamente significante, exercendo influência positiva sobre a variável dependente em ambos os métodos. Contudo, no período posterior à introdução da dummy, há perda de significância estatística das NSFP, também em ambos os métodos e modelos.

A relação positiva encontrada entre a DLSP e a NFSP indica que à medida que cresce a necessidade de financiamento do governo, seja devido aos juros nominais ou ao nível do gasto público frente à arrecadação de tributos (superá-

7 O tripé macroeconômico representa a adoção conjunta do regime de metas de inflação, disciplina fiscal e regime de câmbio flutuante. 
vit), cresce também a dívida líquida. Um fato importante diz respeito à perda de significância da NFSP em relação ao período pós-dummy, indicando que a política de superávit primário recente se mostra incapaz de afetar a dívida líquida, ou seja, reforça a ideia de que no período que sucedeu o ano de 2011 houve maior endividamento.

Em relação à base monetária, os resultados são semelhantes para ambos os modelos e métodos e apontam para a mesma direção. A variável M1 se mostra significativa tanto no período pré-dummy, com sinal do coeficiente positivo, quanto no período pós-dummy, com sinal negativo. A relação positiva entre a DLSP e o M1, no período anterior a 2011, mostra que a oferta de moeda não se ajusta de forma a financiar a dívida. Por outro lado, em relação ao período pós-dummy, um fato merece destaque: a mudança do sinal sofrida pelo coeficiente nas estimações por ambos os métodos. Tais resultados sugerem que houve mudança na relação entre a DLSP e o M1, na qual o estoque monetário passou a provocar reduções na dívida líquida. Essa relação é interessante e merece maior investigação.

Conforme argumentam Pastore, Gazzano e Pinotti (2014), em um regime de dominância monetária a autoridade monetária persegue apenas o objetivo central da estabilidade dos preços, recusando-se a monetizar os déficits públicos, obrigando, dessa forma, que os déficits sejam financiados sem a emissão de senhoriagem. Os resultados expostos na Tabela 1 sugerem o contrário, ou seja, que o governo passou a utilizar a emissão de moeda como alternativa para reduzir o crescimento da dívida pública, frente à incapacidade do superávit em fazê-lo. Nesse mesmo sentido, Mendonça (2003) encontra evidências de que a tendência de o BCB inflacionar a economia (monetização) é função do tamanho da dívida pública, e, portanto, uma redução de seu estoque acarretaria redução da pressão sobre o $\mathrm{BCB}$, implicando maior credibilidade da política monetária.

Partindo desse contexto, é importante ressaltar que a Lei de Responsabilidade Fiscal (Lei Complementar $n^{\circ} 101$, de 4 de maio de 2000) estabelece que o $\mathrm{BCB}$ não pode financiar diretamente os déficits públicos. Por outro lado, o $\mathrm{BCB}$ pode comprar títulos emitidos pela União para refinanciar a dívida mobiliária federal que estiver vencendo na sua carteira (BRASIL, 2000). Ou seja, possibilita a expansão da base monetária para fechar as contas públicas: "[...] O déficit nominal de dezembro foi financiado mediante expansões na dívida mobiliária, na dívida bancária líquida, nas demais fontes de financiamento interno, que incluem a base monetária [...]" (BRASIL, 2016).

Em um cenário no qual a autoridade fiscal persiste a geração de gastos sem a contrapartida na arrecadação, a relação DLSP/PIB não será estável, apresentando tendência de crescimento, o que pode resultar ou com a autoridade fiscal retomando sua disciplina, ou com a autoridade monetária mudando o regime monetário, em outras palavras, passando a financiar seus déficits via expansão monetá- 
ria, gerando a coleta de senhoriagem necessária à solvência e, em consequência, acelerando a inflação. Logo, a estabilidade da relação DLSP/PIB não é garantida via disciplina fiscal, mas sim através da monetização da dívida. Os trabalhos de Issler e Lima (2000) e Pastore, Gazzano e Pinotti (2014), entre outros, enfatizam a importância das receitas advindas da senhoriagem para a manutenção da sustentabilidade do endividamento público no Brasil.

Dentro do atual contexto da economia brasileira, é importante lembrar que há outro componente importante que reforça essa ideia: o recuo das receitas tributárias. O impacto da redução no ritmo de atividade sobre a arrecadação contribuiu para que as receitas públicas crescessem em ritmo menor que as despesas, resultando na deterioração do resultado primário, apesar das elevações nas alíquotas de alguns tributos, como Contribuição de Intervenção no Domínio Econômico (Cide) e Imposto sobre Operações Financeiras (IOF), e da reversão de desonerações. Além desses, o Congresso aprovou a PEC 140/2015 (Brasil, 2015b), que estabelece a volta da Contribuição Provisória sobre Movimentação Financeira (CPMF).

Os resultados expostos nesta seção sugerem que houve mudança de regime na relação entre as variáveis no período recente. Por um lado, há evidências de que a NFSP deixou de ser significativa na determinação da DLSP. Por outro lado, em virtude da resposta da base monetária em relação à dívida líquida, com coeficiente negativo, há evidências de que, no período que sucedeu o ano de 2011 , a autoridade monetária passou a emitir moeda no intuito de fechar as contas públicas. Esses fatos, em conjunto, são alguns indícios da vigência de um regime de dominância fiscal, de acordo com o descrito por Sargent e Wallace (1981).

\subsection{Vetores Autorregressivos com Mudança Markoviana}

No intuito de verificar se de fato houve alteração no comportamento na relação entre as variáveis durante o período estudado, foram estimados dois modelos VAR com mudança markoviana (MS-VAR). A análise é direcionada à relação entre DLSP, NFSP e M1, uma vez que a estimação do MS-VAR ${ }^{8}$ com todas as variáveis do modelo VAR foi descartada em virtude do grande número de parâmetros estimados frente à quantidade reduzida de observações.

O critério de seleção do número ótimo de defasagens apontou para o modelo com uma defasagem. Nesse sentido, a Tabela 2 apresenta os resultados referentes ao teste de linearidade e de seleção do melhor modelo.

$8 \quad$ O modelo MS-VAR foi estimado através do software WinRATS (v.8.00), utilizando-se o pacote MS-VAR desenvolvido por Doan (2012). 
Tabela 2 - Teste LR para seleção dos modelos

\begin{tabular}{clcc}
\hline Teste & \multicolumn{1}{c}{ Hipótese } & $\begin{array}{c}\text { Log likelihood } \\
\text { ratio (LR) }\end{array}$ & $\begin{array}{c}\text { Modelo } \\
\text { escolhido }\end{array}$ \\
\hline \multirow{2}{*}{ I } & $\begin{array}{l}\mathrm{H}_{0}: \text { O modelo é linear. } \\
\mathrm{H} 1: \text { O modelo é não linear. }\end{array}$ & $83.4065^{*}$ & Não linear \\
& $\begin{array}{l}\mathrm{H}_{0}: \mathrm{MSM}(2)-\mathrm{VAR}(1) \equiv \mathrm{MSMH}(2)-\mathrm{VAR}(1) \\
\text { II }\end{array}$ & $65.3656^{* *}$ & $\begin{array}{c}\mathrm{MSMH}(2)- \\
\text {-VAR(1) }\end{array}$ \\
\hline
\end{tabular}

Fonte: Elaboração própria.

Nota: Rejeição da hipótese nula: * 5,00\% **10,00\%; a sigla MSM(M)-VAR(p) diz respeito a um modelo de ordem $p$ com mudança na média e $M$ regimes distintos, para o presente caso: $p=1$ e $M=2$. Por outro lado, a sigla MSMH(M)-VAR(p) representa o mesmo modelo, exceto pelo relaxamento da restrição de erros homocedásticos.

Os resultados do teste LR de linearidade indicam que a relação entre as variáveis é não linear, conforme foi anteriormente identificado através do teste de Bai (1994), justificando a utilização do método MS-VAR, em oposição ao VAR padrão. Em relação à seleção do melhor modelo, o teste indica desigualdade entre o modelo com restrição de erros homocedásticos e o modelo no qual essa restrição é relaxada. Nesse cenário, o modelo irrestrito é selecionado no intuito de se preservar graus de liberdade. Dessa forma, os modelos VAR(1) estimados seguem um processo de mudança markoviana na média em dois regimes.

A Tabela 3 apresenta os resultados referentes ao modelo MSMH(2)-VAR(1).

Tabela 3 - Resultados do modelo MSMH(2)-VAR(1)

\begin{tabular}{lccc}
\hline \multicolumn{1}{c}{ Coeficientes } & $\boldsymbol{\Delta D L S P}_{\mathbf{t}}$ & $\mathbf{\Delta N F S P}_{\mathbf{t}}$ & $\mathbf{\Delta M}_{\mathbf{t}}$ \\
\hline \multirow{2}{*}{ - Regime i } & 0.0028 & 0.0058 & -0.0009 \\
& {$[0.5499]$} & {$[0.1512]$} & {$[-0.1306]$} \\
$\mu$ - Regime j & -0.0024 & 0.0186 & $-0.0121^{* *}$ \\
& {$[-0.5391]$} & {$[0.5432]$} & {$[-1.7032]$} \\
$\Delta \mathrm{DLSPt}-1$ & $0.8348^{*}$ & $0.0139^{*}$ & $0.0458^{* *}$ \\
& {$[29.4427]$} & {$[3.7401]$} & {$[1.8451]$} \\
$\Delta \mathrm{NFSPt}-1$ & $-0.8634^{*}$ & $0.9399^{*}$ & 0.0232 \\
& {$[3.4749]$} & {$[33.3478]$} & {$[3.3699]$} \\
$\Delta \mathrm{M} 1_{\mathrm{t}-1}$ & $-0.0802^{* *}$ & -0.121 & $0.8627^{*}$ \\
Log Likelihood & {$[-1.8412]$} & {$[-0.5852]$} & {$[24.1793]$} \\
\hline
\end{tabular}

Fonte: Elaboração própria.

Nota: "Significante a 5,00\%; ** significante a 10,00\%; [ ] estatística $t$. 
Pode-se observar que, em relação às médias ( $\mu$ ), houve mudança significativa entre regimes apenas em relação à variável M1 (j), com ampliação do coeficiente em termos absolutos. O sinal negativo desse coeficiente sugere que, no regime j, a emissão de moeda é menor em relação ao regime i. Por outro lado, embora o sinal da média da DLSP tenha mudado entre regimes, esse coeficiente não é estatisticamente significante.

Observa-se que a dívida líquida é bilateralmente influenciada pela NFSP e M1. Por um lado, esse resultado demonstra que a geração de superávits leva em consideração a manutenção de uma relação DLSP/PIB estável, devido à resposta no sentido de elevação do superávit frente ao aumento do estoque da dívida. Por outro, mostra também que a moeda influencia a dívida negativamente, sugerindo que o governo realiza coleta de senhoriagem.

A necessidade de financiamento é determinada pela própria variável e pela dívida líquida, demonstrando que, de fato, há preocupação do governo no sentido de manter a relação DLSP/PIB estável. Por outro lado, o M1 é também influenciado pela relação DLSP/PIB, na qual o crescimento desta última precede a elevação do M1, ou seja, da base monetária.

Prosseguindo-se a análise do modelo MSMH(2)-VAR(1), a Tabela 4 apresenta a matriz de probabilidade de transição entre os dois regimes. É possível observar que ambos os regimes $i$ e j, possuem alta persistência. Estando no regime $i$, a probabilidade de permanência no regime atual é de $93.52 \%$, enquanto a probabilidade de mudança para o regime j é de $6.48 \%$.

Tabela 4 - Matriz de transição do modelo MSMH(2)-VAR(1)

\begin{tabular}{lcc}
\hline Transição & Regime i & Regime j \\
\hline Regime $i$ & $93.52 \%$ & $6.48 \%$ \\
Regime j & $7.83 \%$ & $92.17 \%$ \\
\hline
\end{tabular}

Fonte: Elaboração própria.

No mesmo sentido, estando no regime $j$ a probabilidade de permanência nesse regime é de $92.17 \%$, enquanto a probabilidade de mudança para o regime $i$ é de $7.83 \%$, evidenciando a também alta persistência desse regime. A Figura 3 ilustra a probabilidade suavizada para ambos os regimes ao longo do período investigado.

É possível observar que, de forma geral, não há um regime notoriamente dominante durante todo o período analisado. Entretanto, ao direcionar a análise para períodos mais curtos, é possível observar a prevalência de um regime sobre o outro. Por exemplo, o regime $i$ inicia no ano de 2003 com elevada probabilidade, sendo essa probabilidade revertida ao final desse ano, havendo mudança para o regime j durante, aproximadamente, cinco anos. Por outro lado, percebe-se que, 
em 2008, essa probabilidade é novamente revertida para prevalência do regime $i$ - que excluindo um vale no ano de 2012 - é praticamente vigente até o período atual.

Figura 3 - Probabilidades do modelo MSMH(2)-VAR(1)
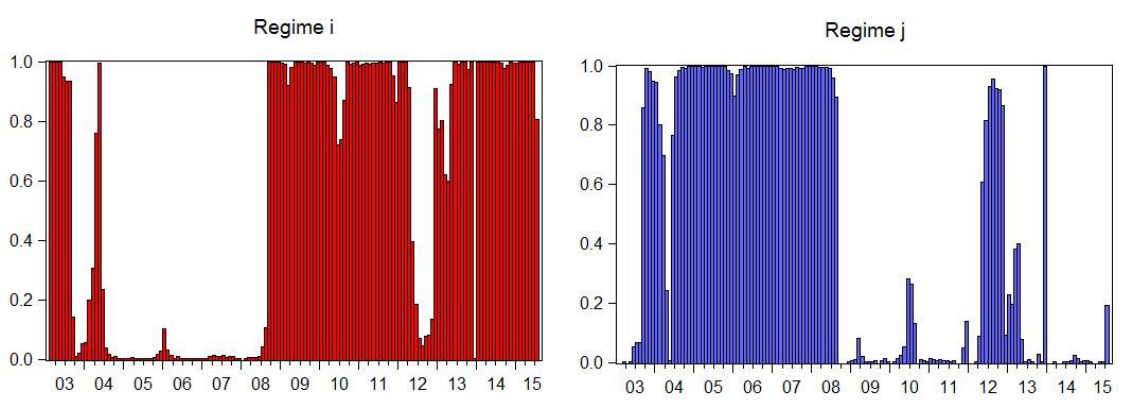

Fonte: Elaboração própria.

Um ponto relevante em relação às probabilidades dos regimes é o fato de a probabilidade do regime $i$ ser claramente prevalecente em períodos considerados conturbados, tal como: crise de confiança pós-eleições em meados de 2002, período no qual Blanchard (2004) verifica a existência de uma relação de dominância fiscal no Brasil; crise dos títulos sub-prime em 2008 e crise político-econômica vivenciada pela economia brasileira no período recente. Esse fato sugere que os regimes são interligados e a condição de estabilidade econômico-financeira é um importante determinante da transição entre regimes, bem como do comportamento da moeda, conforme sugere o modelo.

Também através do método MS-VAR, Fialho e Portugal (2005) buscam investigar a interação entre a taxa Selic e o superávit primário. Os resultados indicaram que ambas as políticas são substitutas, em que uma passará a ser expansionista se a outra se tornar contracionista e vice-versa. Além disso, verificou-se o comportamento compatível com uma autoridade monetária dominante, com a autoridade fiscal se comportando passivamente.

Em resumo, os resultados do modelo MSMH(2)-VAR(1) sugerem a existência de precedência temporal entre elevações do estoque da dívida e da geração de superávits e emissão de moeda. Um fato que merece destaque é a mudança de média sofrida pelo M1 em relação ao regime j, atentando para o fato de que, em tal regime, a emissão de moeda é reduzida. Vale ressaltar que os resultados encontrados a partir do modelo MSMH(2)-VAR(1) estão em consonância com os resultados obtidos nas seções anteriores, apontando para uma mudança estrutural na relação entre as variáveis no período recente. 


\section{Considerações Finais e Discussões}

Não obstante o esforço da autoridade monetária referente às diversas elevações dos juros, a taxa de inflação se perpetua em níveis ainda elevados. Dessa forma, são inevitáveis críticas ao modelo atual de combate à inflação, recaindo em um possível esgotamento do regime de metas inflacionárias e da regra de reação do BCB, conforme proposto por Taylor (1993). Em outras palavras, sob regime de dominância fiscal, o aumento na taxa de juros é o melhor mecanismo de combate à inflação?

A literatura argumenta que, em uma situação de dominância fiscal, o nível da dívida pública é capaz de influenciar diretamente a dinâmica da inflação. Além disso, a política monetária contracionista, na forma de elevações da taxa de juros, contribui ainda mais para a deterioração das condições fiscais via elevação do montante pago com juros nominais. Kumhof, Nunes e Yakadina (2010) chegam à conclusão de que economias sob o regime de dominância fiscal devem estabelecer primeiramente a disciplina nos gastos públicos, previamente ao comprometimento em alcançar metas inflacionárias. A razão disso está relacionada ao elevado custo, em termos de volatilidade das variáveis macroeconômicas, de se praticar política monetária sob uma relação de dominância fiscal.

A questão que surge é: sob regime de dominância fiscal, qual deve ser a postura do $\mathrm{BCB}$ ? A resposta para esse questionamento pode ser dada a partir dos condicionantes que levam à eficácia do regime de metas de inflação. É bem sabido que quando a economia brasileira abandonou o regime de câmbio fixo e passou a adotar o regime de câmbio flutuante, passou-se a utilizar a âncora monetária como mecanismo de combate à inflação.

A partir daí, o regime de metas de inflação foi implantado e a taxa de juros passou a ser o instrumento de resposta à alta generalizada dos preços. Nesse caso, é importante ressaltar que a eficácia de uma política monetária restritiva no combate à inflação, sob regime de câmbio flutuante, está condicionada ao comprometimento fiscal do governo. Ou seja, uma deterioração das contas públicas reduz o poder de influência da política monetária na condução da inflação para sua meta, tendo-se em vista que, à medida que a autoridade monetária aumenta a taxa de juros com o intuito de reduzir a inflação, também aumenta a pressão sobre as contas públicas, uma vez que parte da dívida pública é indexada à taxa Selic.

No contexto brasileiro, talvez o caminho mais curto seja a retomada da austeridade no gasto público e a reversão da trajetória negativa do superávit primário. Portanto, a conclusão da presente pesquisa é de que a atual trajetória das finanças públicas se mostra desordenada e representa uma ameaça à estabilidade de preços. Primeiramente, cabe ao governo retomar a disciplina fiscal para reverter a trajetória desfavorável do resultado primário, no intuito de fornecer os subsídios para 
estabilização, ou mesmo, redução da relação dívida líquida/PIB e, principalmente, a razão dívida bruta/PIB. Os ganhos de credibilidade da política fiscal regrada contribuirão para o desempenho da política monetária, possibilitando o abrandamento da elevada taxa de juros e a redução do serviço da dívida.

\section{Referências}

DE AGUIAR, M. T. Dominância fiscal e regras de reação fiscal: uma análise empírica para o Brasil. 2007. 73 p. Dissertação (Mestrado) - Universidade de São Paulo, 2007.

DE ARAÚJO, J. M.; BESARRIA, C. D. N. Relações de dominância entre as políticas fiscal e monetária: uma análise para a economia brasileira no período de 2003 a 2009. Revista de Economia, v. 40, p. 55-70,2014.

DE ÁZARA, A. Dominância fiscal e suas implicações sobre a política monetária no Brasil: uma análise do período 1999-2005. 2006. Dissertação (Mestrado) - Fundação Getúlio Vargas, 2006. p. 1-84.

BAI, J. Least squares estimation of a shift in linear processes. Journal of Time Series Analysis, V. 15, p. 453-472, 1994.

BLANCHARD, O. Fiscal dominance and inflation targeting: lessons from Brazil. NBER Working Pappers Series, 2004. Disponível em: http://www.nber.org/papers/w10389. Acesso em: 14 abr. 2015.

BRASIL. Lei complementar $n^{\circ}$ 101, de 4 de maio de 2000. Brasília: Presidência da República, 2000. Disponível em: http://www.planalto.gov.br/ccivil\{\\}03/leis/LCP/Lcp101. Acesso em: 19 mar. 2016.

BRASIL. Relatório de inflação. Brasília: Banco Central do Brasil, 2015a. v. 10. Disponível em: http://www.bcb.gov.br/htms/relinf/port/2015/12/ri201512P.pdf. Acesso em: 23 dez. 2015.

BRASIL. Política fiscal - nota para a imprensa. Brasília, 2016. Disponível em: http://www.bcb. gov.br/?ECOIMPOLFISC. Acesso em: 05 fev. 2016.

BRASIL. Relatório da inflação. Brasília, 2010. p. 106-111. Disponível em: http://www.bcb.gov. br/htms/relinf/port/2010/06/ri201006b6p.pdf. Acesso em: 13 jan. 2016.

BRASIL. Constituição (1988). Proposta de Emenda à Constituição n ${ }^{\circ} 140$ de 2015 b. Acrescenta o art. 90-A ao Ato das Disposições Constitucionais Transitórias. 2015. Disponível em: https://www.camara.leg.br/proposicoesWeb/prop_mostrarintegra;jsessionid =073A2BE7B66154BCEE70BF393298564F.proposicoesWeb2 ?codteor = 1396225Efilename $=$ Avulso+-PEC+140/2015. Acesso: 05 fev. 2016.

CLARIDA, R. et al. Monetary policy rules in practice: some international evidence. NBER Working Papers Series, n. 6254, p. 1033-1067, 1998.

COPOM. Ata do COPOM, 199 Reunião. Brasília: Banco Central do Brasil, 2016. Disponível em: http://www.bcb.gov.br/?copom199. Acesso em: 30 jun. 2016. 
DOAN, T. RATS programs to replicate Krolzig MS-VAR's for six country models. 2012. Disponível em: http://econpapers.repec.org/RePEc:boc:bocode:rtz00108. Acesso em: 11 jan. 2016.

FAVERO, C. A.; GIAVAZZI, F. Inflation targeting and debt: lessons from Brazil. NBER Working Papers Series, p. 1-5, 2004. Disponível em: http://www.nber.org/papers/w10390. Acesso em: 19 dez. 2015.

FERREIRA, L. A. M. Dominância fiscal ou dominância monetária no Brasil: uma análise do regime de metas de inflação. 2015. 60 p. Dissertação (Mestrado) - Universidade Federal de Uberlândia, 2015.

FIALHO, M. L.; PORTUGAL, M. S. Monetary and fiscal policy interactions in Brazil: an application of the fiscal theory of the price level. Estudos Econômicos, v. 35, n. 4, p. 657685, 2005. Disponível em: http://www.scielo.br/scielo.php?script $=\operatorname{sci}\{\backslash\}$ arttext $\{\mathcal{E}\}$ pid $=$ S0101-41612005000400003 $\{\mathcal{E}\} \mathrm{lng}=\operatorname{en}\{\mathcal{E}\}$ nrm. Acesso em: 19 dez. 2015 .

GADELHA, S. R. D. B.; DIVINO, J. A. Dominância fiscal ou dominância monetária no Brasil? Uma análise de causalidade. Economia Aplicada, v. 12, n. 4, p. 659-675, 2008. Disponível em: http://www.scielo.br/scielo.php?script $=$ sci $\left\{\backslash \_\right.$arttext $\{\mathcal{E}\}$ pid $=$ S1413$80502008000400006\{\mathcal{E}\}$ lng $=$ pt $\{\mathcal{E}\}$ nrm. Acesso em: 24 abr. $20 \overline{1} 5$.

IPEADATA. M1 - Fim de Período. Disponível em: http://www.ipeadata.gov.br. Acesso em: 05 fev. 2016.

ISSLER, J. V.; LIMA, L.R. Public debt sustainability and endogenous seigniorage in Brazil: time-series evidence from 1947-1992. Journal of Development Economics, v. 62, p. 131-147, 2000 .

KROLZIG, H.M. Markov - Switching Vector Autoregressions: modelling, statistical inference, and application to business cycle analysis. Berlin: Springer, 1997.

KUMHOF, M.; NUNES, R.; YAKADINA, I. Simple monetary rules under fiscal dominance. Journal of Money, Credit 8 Banking (Wiley-Blackwell), v. 42, n. 1, p. 63-92, 2010.

LEE, J.; STRAZICICH, M. C. Minimum LM unit root test with one structural break. Economics Bulletin, v. 33, p. 2483-2492, 2013.

LEE, J.; STRAZICICH, M. C. Minimum lagrange multiplier unit root test with two structural breaks. The Review of Economics and Statistics, v. 85, n. 4, p. 1082-1089, 2003.

MAIA, S. F. Modelos de vetores autorregressivos: uma nota introdutória. In: Texto para Discussão, $n^{\circ}$ 60, Programa de Mestrado em Economia- UEM, Maringá, 2001. p. 1-32.

MAKA, A. On testing the phillips curves, the IS curves, and the interaction between fiscal and monetary policies. 2013. 96 p. Tese (Doutorado) - Fundação Getúlio Vargas, 2013. Disponível em: https://bibliotecadigital.fgv.br/dspace/bitstream/handle/10438/ 11450/DissertationAlexisMaka.pdf?sequence $=1\{\mathcal{E}\}$ isAllowe. Acesso em: 11 jan. 2016.

MARCONI, N. Indexação e taxa de juros. Revista Conjuntura Econômica, n. 692, p. 20-22, 2015. 
MARQUES JUNIOR, K. Há dominância fiscal na economia brasileira? Uma análise empírica para o período do governo Lula. 2009. Dissertação (Mestrado) - Universidade Federal do Paraná, 2009.

MENDONÇA, H. F. de. O comportamento da política fiscal brasileira no século XXI: uma análise a partir do impulso fiscal. Revista Economia, v. 13, n. 2, p. 281-301, 2012.

MENDONÇA, H. F. Três ensaios sobre a dívida pública e a determinação da taxa de juros na economia brasileira. 2003. 78 p. Monografia - Escola de Administração Fazendária ESAF, 2003. Disponível em: https://sisweb.tesouro.gov.br/apex/apex_util.get_blob?s=650 $6141776407 \mathcal{E} \mathrm{a}=2521 \mathcal{E} \mathrm{c}=218903920635965140 \mathcal{E} \mathrm{p}=3 \mathcal{E} \mathrm{k} 1=217 \mathcal{E} \mathrm{k} \overline{2}=\mathcal{E} \mathrm{ck}=\bar{j}$ SkXIoBzH3 eAPIQF5GVdC8iOtEHLQEpQhn8FIjA9EOB4j-aA5AOt8n1yKZJVvjU6r5xmg8o8WHcZgoDEOOTkHwËrt=IR. Acesso em: 01 fev. 2016.

ORNELLAS, R.; PORTUGAL, M. S. Fiscal and monetary policy interaction in Brazil. In: ENCONTRO BRASILEIRO DE ECONOMETRIA, 33., 2011, Foz do Iguaçu; ENCONTRO BRASILEIRO DE ECONOMETRIA, 33., 2011, Foz do Iguaçu. Anais eletrônicos [...]. Rio de Janeiro: Sociedade Brasileira de Econometria, 2011.

PASTORE, A. Uma guinada de 360 graus. O Estado de São Paulo, 2015. Disponível em: http:// economia.estadao.com.br/noticias/geral, uma-guinada-de-360-graus, 1757209. Acesso em: 31 jan. 2016.

PASTORE, A.; GAZZANO, M.; PINOTTI, M. Inflação e crises: o papel da moeda. [S.1.]: Elsevier Brasil, 2014.

PERRON, P. The great crash, the oil price shock, and the unit root hypothesis. Econometrica: Journal of the Econometric Society, v. 57, n. 6, p. 1361-1401, 1989.

PORTILLO, R.; USTYUGOVA, Y. a model for monetary policy analysis in Uruguay. Internacional Monetary Fund Working Paper, n. 15/170, 2015.

ROCHA, F.; SILVA, E.P. Teoria fiscal do nível de preços: um teste para a economia brasileira no período 1966-2000. Pesquisa e Planejamento Econômico, v. 34, n. 3, p. 419-436, 2004.

SARGENT, T. J.; WALLACE, N. Some unpleasant monetarist arithmetic. Federal Reserve Bank of Minneapolis Quarterly Review, v. 5, n. 3, p. 1-17, 1981. Disponível em: https://www. minneapolisfed.org/research/qr/qr531.pdf. Acesso em: 29 mar. 2015.

SCHYMURA, L. G. A sombra da dominância fiscal e a reação do sistema político. Revista Conjuntura Econômica, n. 69, p. 8-11, 2015. Disponível em: www.conjunturaeconomica. com.br. Acesso em: 23 dez. 2015.

DA SILVA, E. K.; MAIA, S. F. Metas inflacionárias: um estudo empírico para o Brasil. Economia e Desenvolvimento, v. 4, n. 2, p. 259-298, 2005.

SIMS, C. A. Simple model for study of the determination of the price level and the interaction of monetary and fiscal policy. Economic Theory, v. 4, n. 3, p. 381-399, 1994.

SIMS, C. A. Macroeconomic and reality. Econometrica: Journal of the Econometric Society, v. 48, p. 1-48, 1980. 
TANNER, E.; RAMOS, A. M. Fiscal sustainability and monetary versus fiscal dominance: evidence from Brazil, 1991-2000. Applied Economics, v. 35, n. 7, p. 859-873, 2003.

TAYLOR, J. B. Discretion versus policy rules in pratice. 1993. p. 195-214. Disponível em: http:// dx.doi.org/10.1016/0167-2231(93)90009-L. Acesso em: 16 maio 2012.

TOMBINI, A. Pronunciamento do Ministro Alexandre Tombini, Presidente do Banco Central do Brasil, na Comissão de Assuntos Econômicos do Senado. Brasília: Banco Central do Brasil, 2015. 13 p.

WOODFORD, M. Monetary policy and price level determinacy in a cash-in-advance economy. Economic Theory, v. 4, n. 3, p. 345-380, 1994. ISSN 09382259.

ZIVOT, E.; ANDREWS, D. W. K. Further evidence on the great crash, the oil-price shock, and the unit-root hypothesis. Journal of Business 8 Economic Statistics, v. 10, n. 3, p. 251-270, 1992.

\section{Apêndice A - Testes aplicados}

Tabela 5 - Testes de raiz unitária das variáveis em nível

\begin{tabular}{lcccccccc}
\hline Variável & ADF & $\begin{array}{c}\text { V.C } \\
\mathbf{( 5 , 0 0 \% )}\end{array}$ & PP & $\begin{array}{c}\text { V.C } \\
\mathbf{( 5 , 0 0 \% )}\end{array}$ & KPSS & $\begin{array}{c}\text { V.C } \\
\mathbf{( 5 , 0 0 \% )}\end{array}$ & ERS & $\begin{array}{c}\text { V.C } \\
\mathbf{( 5 , 0 0 \% )}\end{array}$ \\
\hline CAMBIO & -1.53 & -3.44 & -0.92 & -3.44 & 0.32 & 0.14 & -0.77 & -2.98 \\
$\Delta$ CAMBIO & $-10.02^{*}$ & -3.44 & $-10.03^{*}$ & -3.44 & $0.03^{*}$ & 0.14 & $-6.33^{*}$ & -2.98 \\
DLSP & -1.26 & -3.44 & -1.45 & -3.44 & 0.14 & 0.14 & -0.74 & -2.98 \\
$\Delta$ DLSP & $-10.85^{*}$ & -3.44 & $-10.84^{*}$ & -3.44 & $0.06^{*}$ & 0.14 & $-9.80^{*}$ & -2.98 \\
EMBI & -2.96 & -3.44 & -2.70 & -3.44 & 0.24 & 0.14 & -0.97 & -2.98 \\
$\Delta$ EMBI & $-10.01^{*}$ & -3.44 & $-9.94^{*}$ & -3.44 & $0.05^{*}$ & 0.14 & $-10.06^{*}$ & -2.98 \\
EXPECT & $-4.61^{*}$ & -3.44 & $-4.33^{*}$ & -3.44 & $0.02 *$ & 0.14 & $-2.41 *$ & -2.98 \\
M1 & -0.47 & -3.44 & -0.16 & -3.44 & 0.34 & 0.14 & -0.11 & -2.98 \\
$\Delta$ M1 & $-14.34^{*}$ & -3.44 & $-14.45^{*}$ & -3.44 & $0.04^{*}$ & 0.14 & -2.67 & -2.98 \\
SELIC & -1.99 & -3.44 & -1.44 & -3.44 & 0.19 & 0.14 & -2.40 & -2.98 \\
$\Delta$ SELIC & $-5.23^{*}$ & -3.44 & $-3.37^{*}$ & -3.44 & $0.06^{*}$ & 0.14 & $-3.64^{*}$ & -2.98 \\
NFSP & $-10.55^{*}$ & -3.44 & $-10.46^{*}$ & -3.44 & 0.07 & 0.14 & $-10.35^{*}$ & -2.98 \\
\hline
\end{tabular}

Fonte: Elaboração própria.

Nota: * Estacionária a 5,00\%. 
Tabela 6 - Testes de raiz unitária com quebra estrutural das variáveis em nível

\begin{tabular}{|c|c|c|c|c|c|c|c|c|}
\hline \multirow[t]{2}{*}{ Variável } & \multicolumn{2}{|c|}{$\begin{array}{l}\text { Perron } \\
\text { (1989) }\end{array}$} & \multicolumn{2}{|c|}{$\begin{array}{c}\text { Zivot-Andrews } \\
\text { (1992) }\end{array}$} & \multicolumn{2}{|c|}{$\begin{array}{l}\text { Lee-Strazich } \\
\text { (2013) }\end{array}$} & \multicolumn{2}{|c|}{$\begin{array}{l}\text { Lee-Strazich } \\
\text { (2003) }\end{array}$} \\
\hline & $\mathbf{P}$ & Quebra & $\mathbf{Z A}$ & Quebra & LM & Quebra & LM & Duas quebras \\
\hline CAMBIO & -1.58 & 2008.08 & -3.97 & Set 2010 & -1.37 & Jul 2010 & -1.48 & $\begin{array}{l}\mathrm{D}_{1 \mathrm{t}}: \text { Ago } 2008 \\
\mathrm{D}_{2 \mathrm{t}}: \text { Set } 2010\end{array}$ \\
\hline DLSP & -1.75 & 2008.08 & -4.46 & Mar 2012 & -2.22 & Abr 2014 & -2.36 & $\begin{array}{l}\mathrm{D}_{1 \mathrm{t}}: \text { Ago } 2009 \\
\mathrm{D}_{2 \mathrm{t}}: \text { Jun } 2013\end{array}$ \\
\hline EMBI & -2.88 & 2008.08 & -3.74 & Jul 2007 & -1.68 & Out 2005 & -1.77 & $\begin{array}{l}D_{1 t}: \text { Nov } 2007 \\
D_{2 t}: \text { Ago } 2009\end{array}$ \\
\hline M1 & -0.65 & 2008.08 & -2.37 & Mai 2009 & -3.00 & Jun 2009 & -3.78 & $\begin{array}{l}D_{1 t}: \text { Out } 2007 \\
D_{2 t}: \text { Abr } 2009\end{array}$ \\
\hline SELIC & -2.49 & 2008.08 & -4.44 & Dez 2012 & -0.71 & Mar 2013 & -0.72 & $\begin{array}{l}D_{11}: \text { Abr2012 } \\
D_{2 t}: \text { Out } 2012\end{array}$ \\
\hline NFSP & -0.26 & 2008.08 & -2.88 & Dez 2012 & -2.45 & Jan 2014 & -3.57 & $\begin{array}{l}D_{1 t}: \text { Jan } 2009 \\
D_{2 t}: \text { Mai } 2001\end{array}$ \\
\hline
\end{tabular}

Fonte: Elaboração própria.

Nota: *Estacionária com quebra estrutural a 5,00\%.

Tabela 7 - Testes de raiz unitária das variáveis transformadas

\begin{tabular}{lcccccccc}
\hline Variável & ADF & $\begin{array}{c}\text { V.C } \\
\mathbf{( 5 , 0 0 \% )}\end{array}$ & PP & $\begin{array}{c}\text { V.C } \\
\mathbf{( 5 , 0 0 \% )}\end{array}$ & KPSS & $\begin{array}{c}\text { V.C } \\
\mathbf{( 5 , 0 0 \% )}\end{array}$ & ERS & $\begin{array}{c}\text { V.C } \\
\mathbf{( 5 , 0 0 \% )}\end{array}$ \\
\hline CAMBIO & $-4.17^{*}$ & -2.88 & $-3.44^{*}$ & -2.88 & $0.03^{*}$ & 0.46 & $-3.89^{*}$ & -1.94 \\
DLSP & $-3.34^{*}$ & -2.88 & $-3.34^{*}$ & -2.88 & $0.04^{*}$ & 0.46 & $-2.18^{*}$ & -1.94 \\
EMBI & $-4.22^{*}$ & -2.88 & $-3.73^{*}$ & -2.88 & $0.04^{*}$ & 0.46 & -1.79 & -1.94 \\
EXPECT & $-4.61^{*}$ & -2.88 & $-4.33^{*}$ & -2.88 & $0.02^{*}$ & 0.46 & $-2.41^{*}$ & -1.94 \\
M1 & $-3.65^{*}$ & -2.88 & $-3.76^{*}$ & -2.88 & $0.02^{*}$ & 0.46 & $-3.29 *$ & -1.94 \\
SELIC & $-5.11^{*}$ & -2.88 & $-3.20^{*}$ & -2.88 & $0.03^{*}$ & 0.46 & $-2.55^{*}$ & -1.94 \\
NFSP & $-3.15^{*}$ & -2.88 & $-3.37^{*}$ & -2.88 & $0.03^{*}$ & 0.46 & $-2.89^{*}$ & -1.94 \\
\hline
\end{tabular}

Fonte: Elaboração própria.

Nota: "Estacionária a 5,00\%. 
Tabela 8 - Testes de número ótimo de defasagens

\begin{tabular}{c|ccc|c|ccc}
\hline \multicolumn{4}{c}{ Modelo VAR(4) } & \multicolumn{4}{c}{ Modelo MS-VAR(1) } \\
\hline Def. & AIC & SIC & HQ & Def. & AIC & SIC & HQ \\
\hline 0 & -20.09 & -18.36 & -18.45 & 0 & -9.99 & -9.93 & -9.96 \\
1 & -30.85 & -28.62 & -29.30 & 1 & $-13.77^{*}$ & $-13.52^{*}$ & $-13.67^{*}$ \\
2 & -32.12 & $-28.92^{*}$ & $-30.20^{*}$ & 2 & -13.76 & -13.32 & -13.58 \\
3 & -32.16 & -27.99 & -29.86 & 3 & -13.67 & -13.32 & -13.47 \\
4 & $-32.19^{*}$ & -26.95 & -29.41 & 4 & -13.62 & -13.32 & -13.22 \\
\hline
\end{tabular}

Fonte: Elaboração própria.

Tabela 9 - Testes de autocorrelação serial

\begin{tabular}{ccccc|ccccc}
\hline \multicolumn{4}{c|}{ Modelo VAR(4) } & \multicolumn{5}{c}{ Modelo MS-VAR(1) } \\
\hline Def. & $\mathbf{d = 1}$ & $\mathbf{d = 2}$ & $\mathbf{d = 3}$ & $\mathbf{d = 4}$ & Def. & $\mathbf{d = 1}$ & $\mathbf{d = 2}$ & $\mathbf{d = 3}$ & $\mathbf{d = 4}$ \\
\hline 1 & $0.00^{*}$ & $0.00 *$ & $0.00^{*}$ & 0.75 & 1 & 0.08 & 0.10 & $0.00 *$ & 0.73 \\
2 & $0.00 *$ & $0.01 *$ & $0.00 *$ & 0.30 & 2 & 0.10 & 0.07 & 0.43 & 0.63 \\
3 & $0.00 *$ & $0.00 *$ & $0.04 *$ & 0.33 & 3 & 0.35 & 0.54 & 0.43 & 0.14 \\
4 & $0.00 *$ & 0.65 & 0.87 & 0.46 & 4 & 0.79 & 0.88 & 0.36 & 0.29 \\
\hline
\end{tabular}

Fonte: Elaboração própria.

Nota: $\mathrm{H}_{0}$ : ausência de autocorrelação.

Figura 4 - Raízes invertidas do polinômio autorregressivo característico
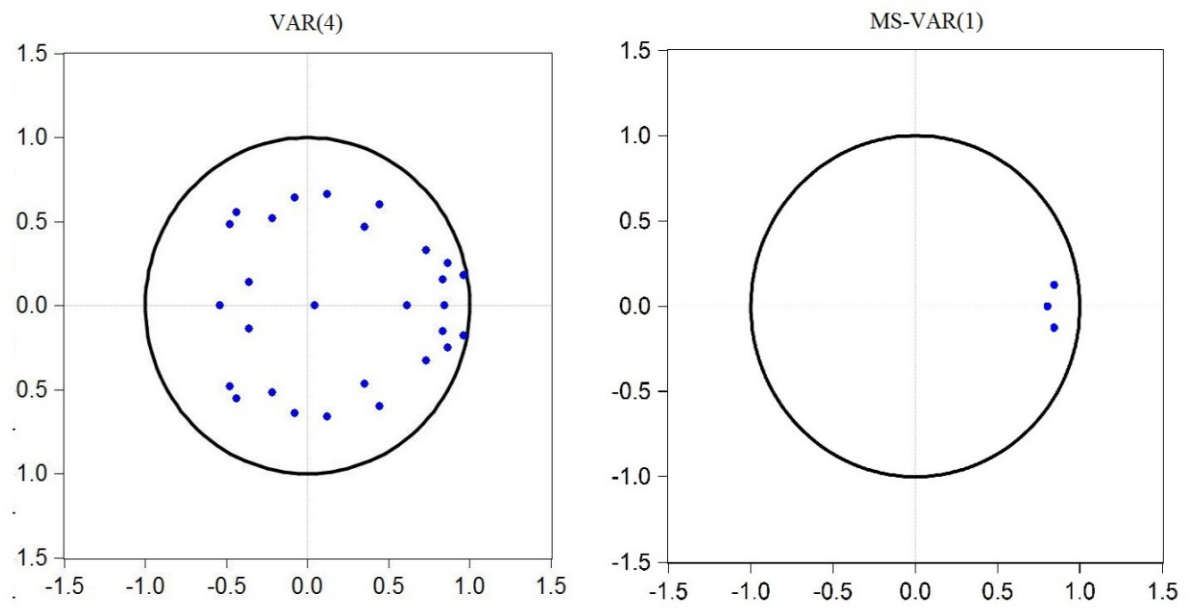

Fonte: Elaboração própria. 
Recebido em: 16/03/2017.

Aceito em: 18/06/2018.

(cc) BY 